\title{
CrimRxiv
}

\section{Changes in Enforcement of Low-Level and Felony Offenses Post-Ferguson: An Analysis of Arrests in St. Louis, Missouri}

Claire Greene, Lee Ann Slocum, Beth M. Huebner, Richard Rosenfeld

Published on: Aug 01, 2019

DOI: $10.21428 / c b 6 a b 371 . b f 51 a e 28$

License: Creative Commons Attribution 4.0 International License (CC-BY 4.0) 
